\title{
Biodiversity offsetting and the reframing of conservation: a reply to ten Kate $\&$ von Hase and Dempsey \& Collard
}

\author{
Evangelia A postolopoulou and William M. Adams
}

$\mathrm{W}$ e are grateful to ten Kate \& von Hase (2016) and Dempsey \& Collard (2016) for their insightful and constructive responses to our article on biodiversity offsetting (Apostolopoulou \& Adams, 2015a). They agree with us that conservationists need to think very carefully about offsetting and its implications for nature conservation. They differ substantially in where that thinking should lead. Ten Kate \& von Hase believe that offsetting is fine if it is done properly. Dempsey \& Collard are profoundly uneasy about its implications, and go deeper into the way conservation is folded into economic development, 'smoothing the way for new industrial scale projects'.

Ten Kate \& von Hase make two principal points. Firstly, they ask that biodiversity offsetting be 'correctly framed' and that offsets are 'regarded in their proper context'. They reiterate 'best practice approaches', in which offsetting is the last resort in a carefully applied mitigation hierarchy that adopts metrics and takes full account of ecosystem condition, functions and processes. But they write as if the idealized Second Life (Second Life, 2016) world of market-based conservation were real. In this alternative reality, markets ensure that those with money and power make decisions that deliver optimal outcomes, the 'value' of things is fully reflected in their 'price', development is socially necessary and thus its environmental consequences should be seen as inevitable, and decisions are made with full knowledge of all the facts. The real world is not like that, as they themselves point out. They note that there are many situations in which offsetting residual impacts is impossible or infeasible, that individual biodiversity offsets and national systems lack clarity on baselines and reference scenarios, exchange rules and metrics, and that standards are not enforced. Results, they note, are 'disappointing'. We agree with all these things. However, in our original article (Apostolopoulou \& Adams, 2015a) we explained why these are not regrettable exceptions to a good rule, but the way offsetting rules themselves work.

Evangelia Apostolopoulou (Corresponding author) School of Geography and the Environment, University of Oxford, OX1 3QY, Oxford, UK

E-mail elia.apostolopoulou@ouce.ox.ac.uk

William M. Adams Department of Geography, University of Cambridge, Cambridge, UK.

Received 21 October 2016. Accepted 21 October 2016.

First published online 21 November 2016.
Yes, offsetting is getting more sophisticated, but no, it does not conserve nature: it moves damage around.

Ten Kate \& von Hase's second point is that offsetting does not reframe conservation: it is just one kind of conservation policy, and all the others continue unchanged. Yes, of course, protected areas, hunting rules and community engagement can and do all continue alongside offsetting. Ideally, again, offsetting could be imagined simply as an extra tool in the conservationist's toolbox. But offsetting is different from these other strategies in the way it ties conservation to land development and economic growth. It does not stop the destruction of nature; it just moves environmental compensation across space and time. So for offsetting to be thought of as a conservation instrument (as it is in most definitions), the definition of conservation has to change. There is also a second problem: offsetting is growing in popularity. Some conservationists like it because they hope it will increase the area of land under conservation management. Developers like it because if they throw money at the problem of environmental impacts (securing conservation land elsewhere) they can get their project approved. Governments like it because they get to simultaneously approve and green-wash big projects, and look as if they can please everyone. Of course, governments should maintain their investment in conservation, but will they? The evidence from the UK, where we have been working, suggests that conservation strategies that please developers (or that are funded by developers) are very attractive, especially during periods of economic crisis and austerity policies (Vaughan, 2016). Under these circumstances it is easy to imagine offsetting, the developer's flexible friend, gaining ground against tight regulation and land management. The expansion of offsetting is therefore not a neutral addition of a new tool for conservation; it precisely impinges on (and threatens to restrict) other kinds of conservation action.

The underlying logic of ten Kate \& von Hase's response is the exact logic we tried to challenge in our article, that biodiversity offsetting if properly implemented would be beneficial for non-human nature and its conservation. Interestingly, ten Kate \& von Hase are wrong for all the right reasons. Even though they try to defend offsetting by agreeing with us that the issue is more than technical, they end up falling into the trap of discussing technicalities. This is important because it reflects how deeply embedded the 
ideological belief in offsetting (and similar apologetic environmental policies that aim to justify the existing socio-economic order) is. This is exactly what we tried to show in our article.

Thus ten Kate \& von Hase argue that the key issue is 'whether governments and companies can apply the necessary high standards' (citing the Business and Biodiversity Offsets Programme), and that without offsetting 'the price set on biodiversity is zero', that 'practical approaches are essential to limit complexity and ensure a workable outcome' and that it is 'unrealistic' to expect that biodiversity loss will be prevented given the current patterns of growth. They also point out that they agree with us 'that this is far more an issue of political will than it is one of handling technical challenges', as if the two could be separated. Our point was rather different. We argue that the technical challenges of offsetting (while considerable and interesting for researchers) are a distraction from the work of conservation and frame the debate over the environmental impacts of development as a technical issue of allocating natural capital, or the stock of biodiversity resources, across space and time in a way that has no social implications. Offsetting reflects the hegemonic discourse of market environmentalism, according to which the only thing to do is to offer recommendations that tweak details of projects that result from pre-decided pro-growth policies. Our goal was to reveal the flaws in this approach. There is a need to open up the possibility of completely rejecting policies that are harmful for both humans and non-human nature and to challenge current patterns of economic development and growth openly.

This is where our analysis meets the analysis of Dempsey \& Collard, who share our concern about biodiversity offsetting. Their thinking leads them to a neat analysis of the politics that lie behind what they rather nicely call 'the gamble that offset proponents are making'. They open up the debate very helpfully, to address the links between the destruction of nature and the driving forces of capitalism. They point out that capitalism can only produce trade-offs: sacrifice zones to which the burden of human demands on nature (and the poor) are shifted. That is precisely what offsetting does.

The conversion of complex ecosystems to simple measurable units is neither trivial nor politically neutral: it is a product of capitalism's specific, socially determined relation to nature. It results from capitalism's exploitative use and development of natural forces as material conditions of capital accumulation (as Burkett, 1997, points out). This means that offsetting's calculations cannot just be fixed by better techniques. They are based on capitalism's understanding of non-human nature as a stock of biodiversity whose value can be captured by price. Offsetting's reductionism reflects and reinforces the neoliberal logic currently powerful in biodiversity conservation, based on the idea that the solution to biodiversity loss is proper accounting to enable the internalization of environmental externalities (e.g. Bayon et al., 2008; TEEB, 2010). To follow this logic to its conclusion, offsetting clearly demands further deregulation of environmental and planning policies to boost economic growth.

Ultimately, as Dempsey \& Collard also point out, biodiversity offsetting reflects, reproduces and deepens the environmental contradictions of capitalism.

They go further, to sketch the tantalizing possibility of conservation as a movement that is capable of challenging international capitalism, and willing to do so. One key to this is that conservation should pick sides, not cosying up to corporations but standing up to them (an argument similar to that of Robinson (2011) who makes the case that conservation should stand at a distance from corporations).

Dempsey \& Collard are right to argue that this is also what we have in mind when we make a call to the conservation movement for 'direct political engagement', or for 'a fierce oppositional' and 'solidarity politics' as they put it. This call is based on our belief that conservation must be more than its mainstream version. As we have pointed out elsewhere (Apostolopoulou \& Adams, 2015b), even though various driving forces have shaped the history of conservation, environmental protection regulations have been won through environmental and social movements (Harvey, 2005; Vlachou, 2005). Moreover, crucially, rolling back environmental regulations designed to protect ecosystems from degradation entails the loss of rights. Of course we have in mind here a much broader definition of conservation that includes all people and social movements fighting against the degradation of nature and places.

Ten Kate \& von Hase are right that the risks and opportunities of biodiversity offsetting as a conservation strategy need to be analysed very carefully. So too, as Dempsey \& Collard point out, do the wider political economic context within which they are operated. We welcome discussion on specific proposals (Dempsey \& Collard refer explicitly to ecological debt, for example). Above all, however, we would like to emphasize the need to place at the core of conservation the big political issues that often remain in the shadows of academic, policy and political debates about conservation: how nature is produced (cf. Smith, 2010), who controls this production of nature, and what an alternative would look like.

\section{References}

Apostolopoulou, E. \& Adams, W.M. (2015a) Biodiversity offsetting and conservation: reframing nature to save it. Oryx, http://dx.doi. org/10.1017/Soo30605315000782.

Apostolopoulou, E. \& Adams, W.M. (2015b) Neoliberal capitalism and conservation in the post-crisis era: the dialectics of 'green' and 'un-green' grabbing in Greece and the UK. Antipode, 47, 15-35.

Bayon, R., Fox, J. \& CARroll, N. (eds) (2008) Conservation and Biodiversity Banking: A Guide to Setting Up and Running

Biodiversity Credit Trading Systems. Earthscan, London, UK. 
BurketT, P. (1997) Nature in Marx reconsidered: a silver anniversary assessment of Alfred Schmidt's concept of nature in Marx. Organization \& Environment, 10, 164-183.

Dempsey, J. \& Collard, R. (2016) If biodiversity offsets are a dead end for conservation, what is the live wire? A response to Apostolopoulou \& Adams. Oryx, http://dx.doi.org/10.1017/ So030605316000752.

Harvey, D. (2005) A Brief History of Neoliberalism. Oxford University Press, Oxford, UK.

Robinson, J.G. (2011) Corporate greening: is it significant for biodiversity conservation? Oryx, 45, 309-310.

SeCOnd Life (2016) Http://secondlife.com [accessed 19 October 2016]. Smith, N. (2010) Uneven Development: Nature, Capital and the Production of Space (3rd edition). Verso, New York, USA.

TEEB (The ECONomics of Ecosystems And Biodiversity) (2010) The Economics of Ecosystems and Biodiversity: Mainstreaming the Economics of Nature: A Synthesis of the Approach, Conclusions and Recommendations of TEEB. The Economics of Ecosystems and Biodiversity, Geneva, Switzerland.

ten Kate, K. \& von Hase, A. (2016) Correct framing of biodiversity offsets and conservation: a response to Apostolopoulou \& Adams. Oryx, http://dx.doi.org/10.1017/Soo30605316001022.
Vaughan, A. (2016) Budget cuts threaten to weaken powers of England's nature watchdog. The Guardian. Https://www. theguardian.com/environment/2016/aug/16/budget-cuts-threatento-weaken-powers-of-englands-nature-watchdog [accessed 21 October 2016].

Vlachou, A. (2005) Environmental regulation: a value-theoretic and class-based analysis. Cambridge Journal of Economics, 29, 577-599.

\section{Biographical sketches}

Elia Apostolopoulou's main research interest is the investigation of the relationship between nature and society in capitalism, with a particular emphasis on the political ecology of nature conservation. Her current research focuses mainly on the reconstruction of nature conservation around the measurement of the economic value of nonhuman nature. BILL ADAMS is interested in changing ideas about nature and its conservation. His current research addresses the politics of landscape-scale conservation and the power of ecosystem services and other metaphors in conservation policy. 